\title{
An Autopsy Case of Amyotrophic Lateral Sclerosis with Waldenström Macroglobulinemia and Anti-MAG Gammopathy
}

\author{
Snejana Jurici $i^{a} \quad$ Annie Laquerrière ${ }^{b}$ \\ Anne-Laure Bedat-Millet ${ }^{a, c}$ Fabrice Jardin ${ }^{d}$ \\ Lucile Musset $^{f}$ Jean-Michel Vallat ${ }^{\mathrm{g}}$ Didier Hannequin ${ }^{\mathrm{a}, \mathrm{e}}$ \\ Olivier Martinaud ${ }^{a}$ \\ ${ }^{a}$ Department of Neurology, ${ }^{b}$ Neuropathology Laboratory, and ${ }^{c}$ \\ Neurophysiology Laboratory, Rouen University Hospital, ${ }^{d}$ Department of \\ Hematology, Centre Henri Becquerel, and ${ }^{\mathrm{e}}$ Inserm U 614, IFRMP, Faculty of \\ Medicine and Pharmacy, Rouen, Immunochemistry Laboratory, Pitié- \\ Salpêtrière University Hospital, Assistance Publique Hôpitaux de Paris, Paris, \\ and ${ }^{g}$ Department of Neurology, National Reference Center for Rare \\ Neuropathies, Limoges University Hospital, Limoges, France
}

\section{Key Words}

Amyotrophic lateral sclerosis · Anti-MAG · Waldenström macroglobulinemia

Abstract

We report the case of a 71-year-old woman with typical signs of bulbar amyotrophic lateral sclerosis (ALS) associated with immunoglobulin M (IgM) monoclonal gammopathy and antiMAG (myelin-associated glycoprotein) antibodies. This unusual association between ALS and anti-MAG antibodies has previously been reported in a single case. Our present case, at neuropathological examination, demonstrated no causative link between anti-MAG antibodies and ALS.

\section{Introduction}

One category of amyotrophic lateral sclerosis (ALS) occurring in 7.5-9\% of the total incidence of ALS [1] is associated with biological abnormalities including monoclonal gammopathy of unknown significance [2]. Monoclonal protein IgM (immunoglobulin M) with anti-MAG (myelin-associated glycoprotein) antibodies may be associated with 
a sensory polyneuropathy. The onset is insidious with numbness and paresthesia predominant in the lower limbs with possible symmetrical weakness and wasting in later stages [3]. An electroneuromyogram (EMG) in anti-MAG neuropathy demonstrates a demyelinating or mixed axonal demyelinating pattern [4]. Peripheral sensory neuropathy is not usually recognized as a feature of ALS [5-7]. The present exceptional case involving ALS, Waldenström macroglobulinemia and anti-MAG gammopathy presents an opportunity to discuss the potential relations between ALS and anti-MAG antibodies.

\section{Case Report}

A 71-year-old woman with no relevant past medical history presented with insidious onset of dysarthria and slurred speech. Eight months later she was speechless and had difficulties in swallowing. She developed weakness in the left hand and after 12 months neurological examination demonstrated diffuse asymmetrical wasting and weakness of the upper limbs, with a slight predominance on the right side. These signs were present to a lesser degree in the lower limbs, associated with fasciculations only in the forearms and in the tongue. The reflexes were brisk. She has no paresthesias and no sensory loss was detected on clinical examination. The patient had no cognitive impairment and used writing for daily communication. EMG was in accordance with ALS criteria [2] but there was reduced amplitude of distal sensory nerve action potentials in the upper and lower limbs (table 1). Cerebral and cervical spinal cord MRIs were normal. Serum creatine kinase level was increased: 1,237 U/l (normal: 50-145). Monoclonal serum IgM total protein was found to be high, $5.29 \mathrm{~g} / \mathrm{l}$ (normal: 0.55-2.10), with normal IgA and IgG proteins. IgM protein demonstrated high anti-MAG activity at 76,200 BTU (normal: $<1,000$ ). Anti-GM2 activity was at a 1/50 level (normal: $<1 / 100$ ), without anti-GM1 activity. Serum free kappa light chains and urine Bence Jones protein were detected. Cerebrospinal fluid analysis revealed normal cell count and a slight increased protein level at $0.57 \mathrm{~g} / \mathrm{l}$ (normal: <0.45). Bone marrow biopsy examination revealed an infiltration by a mixture of small lymphocytes, plasma cells and plasmacytoid lymphocytes of IgM type, suggesting the diagnosis of Waldenström macroglobulinemia. The evolution was marked by asymmetrical global weakness, mainly distal and right-sided, aphagia, and sialorrhea. According to recommendations [8], 4 weeks' treatment with rituximab $\left(375 \mathrm{mg} / \mathrm{m}^{2} /\right.$ week for a body surface of $\left.1.3 \mathrm{~m}^{2}\right)$ and chlorambucil $\left(6 \mathrm{mg} / \mathrm{m}^{2}\right.$ for 42 days) was administered without significant effect. After 17 months, physical examination revealed symmetrical upper and lower limb weakness, with no additional sensory complaints. In spite of no sensory clinical outcome, 5 months after the first EMG there was aggravation of sensory signs with severe reduction of amplitude in the upper and lower limbs for all sensory responses. There was electrical aggravation of motor signs (table 1). The patient died 3 months later from aspiration pneumonia, 20 months after symptom onset. Histological examination revealed the characteristic features of ALS. The lesions consisted of severe loss of anterior horn neuronal cells, with atrophic corticospinal tracts from cervical to lumbar levels and preservation of the posterior columns. Few Bunina bodies were present in the remaining motor neurons. Neuronal loss was observed in the motor nuclei of the brainstem, particularly in the hypoglossal nucleus which contained chromatolytic cells, and to a lesser degree in the vestibular nucleus. Pyramidal tracts of the brainstem were atrophic.

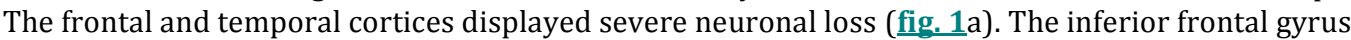
displayed significant loss of Betz cells. Rare ubiquitin-positive round or skein-like inclusions were observed in the spinal cord (fig. 1b, c) and brainstem, whereas the supratentorial structures were negative, except for the dentate gyrus where rare neuronal intracytoplasmic inclusions could be observed (fig. 1d). Immunodetection with antibodies TDP-43 and FUS (fused-in sarcoma) was negative. Neither neuronophagia nor lymphocytic cuffing were observed in the spinal cord, and no lesion suggestive of lymphoma was found. Immunodetection of inflammatory cells using anti-CD3, CD5, CD20, CD68 and CD138 antibodies was entirely negative. Some dorsal roots were examined by electron microscopy. We did observe neither significant decrease in the myelinated fiber density nor widenings of the myelinated lamellae as previously described in anti-MAG neuropathy [9]. 


\section{Discussion}

Our case presents neuropathological confirmation of ALS with high anti-MAG activity. Neuropathological features were in accordance with the diagnosis of certain forms of ALS. Ubiquitin inclusions in the dentate gyrus are the marker of ALS with dementia [10], but in our case these inclusions were rare in accordance with the absence of objective cognitive disorder. The EMG examination for sensory nerve conduction can be abnormal, suggesting a coexisting disease, as in our patient [2]. Paraproteinemia was reported in 7.5-9\% of ALS cases compared with $1 \%$ in the general population [1]. In this category of ALS with paraproteinemia and monoclonal gammopathies, IgM proteins are the more frequent. Anti-GM1 antibodies are found in $90 \%$ of cases and anti-MAG antibodies are exceptionally reported $[5,11,12]$. Among 5 patients with sporadic ALS and sensory neuropathy of unknown cause, 4 had clinical and 5 electrophysiological sensory signs, and only 1 case had a serum IgM paraprotein, but anti-MAG antibodies were not reported [7]. Our patient's bone marrow exam suggested the diagnosis of Waldenström macroglobulinemia. Anti-MAG antibodies were reported in $4 \%$ of Waldenström macroglobulinemia cases [1]. High titer of antiMAG antibodies, as in our case, has been reported in some Waldenström macroglobulinemia cases [13]. The association of anti-MAG antibodies with Waldenström macroglobulinemia and motor neuron disease was only reported in 1 case but with borderline titer [1]. The argument suggesting a neuropathy in the present case is the severe reduction of sensory features on the second EMG, 5 months after the previous one (table 1). Then, in the present case, we raise questions about the possible associations between neuropathy, ALS and anti-MAG antibodies. Sensory involvement (electrophysiological or polyneuropathy) has been found in 10-20\% of ALS cases [7]. Among 88 ALS patients, $22.7 \%$ showed abnormalities in sensory nerve conduction parameters in at least 1 nerve [4]. Another study reported 3 cases associating ALS with clinical and EMG chronic inflammatory demyelination polyradiculoneuropathy [6]. Neuropathological examination in one case fulfilled criteria for both diseases. To our knowledge, there is only 1 case fulfilling both criteria for ALS and peripheral sensory anti-MAG neuropathy, but neuropathological examination was not performed [5]. Initial symptoms were distal paresthesias (unlike in our patient) and rapidly progressive weakness in all four limbs. Clinical examination revealed mildly decreased sensation of vibration and reduced sensation of warmth in the legs and hands and only patellar reflexes were found (unlike in our patient). EMG found demyelinated neuropathy with electrical motor signs. The possible discussion about the relations between ALS and anti-MAG antibodies relies on the immune mechanisms reported in some ALS cases. Several pathogenic mechanisms which may contribute to motor neuron injury and lead to death have been identified in ALS [14]. Oxidative stress, genetic factors, glutamatergic toxicity and mitochondrial dysfunction are well known $[14,15]$. There are also arguments suggesting that cells of the immune system are implicated in the pathogenesis or propagation of ALS. Microglia, which play a major role in inflammatory cascades, have been proven to be activated in spinal ventral horn neurons in ALS [14]. Otherwise, inflammatory markers such as activated macrophages, mast cells and T cells have been reported in spinal cord and brain in ALS [14]. AntiMAG neuropathy is the consequence of antibodies that react with myelin-associated glycoprotein via a complement-mediated mechanism [3]. The very high titer of antiMAG antibodies, as in the present case, could have been considered an argument for a 
causative link, but absence of correlation between anti-MAG titer and severity of neuropathy has been reported [3]. In fact, several arguments suggest there was no relation between neuropathy and the anti-MAG antibodies, because (i) there were no demyelinating neuropathy symptoms, (ii) there was no significant decrease of conduction velocities and (iii) no suggestive neuropathological features. Moreover, 66$75 \%$ of anti-MAG neuropathies respond to rituximab therapy after 1 year of treatment [13] but no responses were observed in patients with ALS and sensory involvement [5, 6,11 . Our patient did not respond to rituximab therapy associated with chlorambucil.

In conclusion, our case is original because of the association between ALS, Waldenström macroglobulinemia and high titer of anti-MAG antibodies. Our investigations including neuropathological examination demonstrate that there was no argument for a causative link between anti-MAG antibodies and ALS.

\section{Acknowledgement}

The authors thank Richard Medeiros, Rouen University Hospital Medical Editor, for editing the manuscript.

\section{Disclosure Statement}

No conflict of interest. 
Table 1. EMG results

\begin{tabular}{|c|c|c|c|c|c|c|}
\hline \multirow[t]{2}{*}{ Nerve } & \multicolumn{2}{|l|}{$\mathrm{ML}, \mathrm{ms}$} & \multicolumn{2}{|l|}{$\mathrm{MA}, \mathrm{mV}$} & \multicolumn{2}{|c|}{$\mathrm{VCM}, \mathrm{m} / \mathrm{s}$} \\
\hline & $12^{1}$ & $17^{1}$ & $12^{1}$ & 171 & $12^{1}$ & $17^{1}$ \\
\hline \multicolumn{7}{|l|}{ Motor conduction } \\
\hline Median (L/R) wrist & $5.4 / 10.5$ & NA & $0.8 / 1.8$ & NA & $39 / 37$ & NA \\
\hline \multicolumn{7}{|l|}{ Ulnar $(\mathrm{L} / \mathrm{R})$} \\
\hline Wrist & $4.6 / 3.3$ & $\mathrm{NA} / 5$ & $2.9 / 4.9$ & $\mathrm{NA} / 1.5$ & $34 / 47$ & NA/46 \\
\hline Forearm & NA/9.2 & NA/8.4 & NA/1.7 & $\mathrm{NA} / 0.9$ & & \\
\hline Peroneal (L/R) ankle & NR/9.6 & NR/NR & $\mathrm{NR} / 1.3$ & NR/NR & $\mathrm{NR} / 28$ & NR/NR \\
\hline Tibial (R) ankle & $\mathrm{NR}$ & NR & NR & NR & NR & NR \\
\hline \multirow[t]{2}{*}{ Nerve } & & \multicolumn{3}{|l|}{$\mathrm{SA}(\mu \mathrm{V})$} & \multicolumn{2}{|l|}{$\operatorname{VCS}(\mathrm{m} / \mathrm{s})$} \\
\hline & & $12^{1}$ & 171 & & $12^{1}$ & 171 \\
\hline \multicolumn{7}{|l|}{ Sensory conduction } \\
\hline \multicolumn{2}{|l|}{ Median (L/R) antidromic } & 6.1/NA & \multicolumn{2}{|c|}{$4.1 / 2.7$} & $50 / \mathrm{NA}$ & $52 / 46$ \\
\hline \multicolumn{2}{|l|}{ Ulnar (L) antidromic } & 2.4 & \multicolumn{2}{|c|}{$\mathrm{NA}$} & 44 & $\mathrm{NA}$ \\
\hline \multicolumn{2}{|l|}{ Radial (L) orthodromic } & 17.2 & \multicolumn{2}{|l|}{5.3} & 61 & 46 \\
\hline \multicolumn{2}{|c|}{ Musculocutaneous (L) antidromic } & NR & \multicolumn{2}{|l|}{ NR } & NR & NR \\
\hline \multicolumn{2}{|l|}{ Sural (L/R) antidromic } & NA/19.8 & \multicolumn{2}{|c|}{$5.4 / 8.7$} & $\mathrm{NA} / 41$ & $44 / 41$ \\
\hline
\end{tabular}

Normal values: median $\mathrm{ML}<3.7, \mathrm{MA}>6, \mathrm{VCM}>48$; cubital $\mathrm{ML}<3, \mathrm{MA}>6, \mathrm{VCM}>48$; tibial $\mathrm{ML}<5, \mathrm{MA}>3$, $\mathrm{VCM}$; peroneal $\mathrm{ML}<5.5$, MA $>6, \mathrm{VCM}>42$; median $\mathrm{SA}>15$, VCS $>45$; cubital $\mathrm{SA}>8$, VCS $>45$; radial $\mathrm{SA}>15$, VCS $>45$; musculocutaneous $\mathrm{SA}>10$, VCS $>40$; sural $\mathrm{SA}>5$, VCS $>40$.

$\mathrm{L}=$ Left; $\mathrm{R}$ = right; $\mathrm{NR}=$ no response; $\mathrm{NA}=$ not recorded; $\mathrm{ML}$ = motor latency; $\mathrm{MA}$ = motor amplitude; $\mathrm{VCM}$ = motor conduction velocity; $\mathrm{SA}=$ sensory amplitude; $\mathrm{VCS}$ = sensory conduction velocity.

${ }^{1}$ Months of delay past onset (i.e. between first signs of ALS and EMG). 

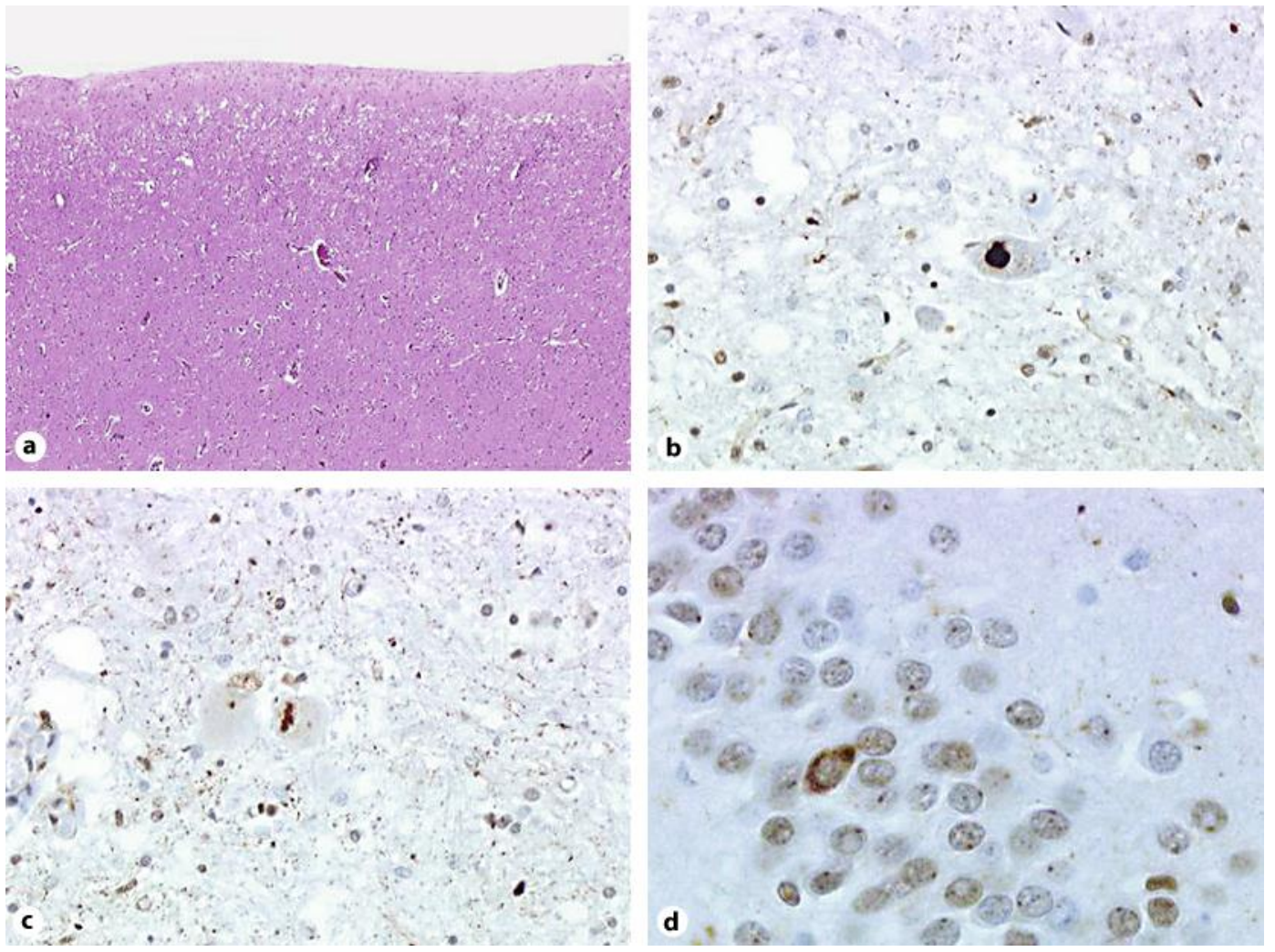

Fig. 1. Histopathology of the cortex (a) and the spinal cord (b-d). a Decreased neuronal density in the frontal cortex, with vanishing lamination and microspongiosis of layers II and III (HE stain; original magnification $\times 25$ ). $\mathbf{b}$ Round ubiquitin-positive intracytoplasmic inclusions in the motor neurons of the cervical spinal cord (original magnification $\times 250$ ). c Skein-like ubiquitin inclusions in the perikarya of chromatolytic motor neurons (original magnification $\times 250$ ). $\mathbf{d}$ Scarce neuronal ubiquitinpositive, TDP-43-and FUS-negative intracytoplasmic inclusions in the dentate gyrus.

\section{References}

$\checkmark 1$ Gordon PH, Rowland LP, Younger DS, Sherman WH, Hays AP, Louis ED, Lange DI, Trojaborg W, Lovelace $\mathrm{RE}$, Murphy PL, Latov N: Lymphoproliferative disorders and motor neuron disease: an update. Neurology 1997;48:1671-1678.

-2 Brooks BR: El Escorial World Federation of Neurology criteria for the diagnosis of amyotrophic lateral sclerosis. Subcommittee on Motor Neuron Diseases/Amyotrophic Lateral Sclerosis of the World Federation of Neurology Research Group on Neuromuscular Diseases and the El Escorial 'Clinical limits of amyotrophic lateral sclerosis' workshop contributors. J Neurol Sci 1994;124(suppl):96-107.

-3 Nobile-Orazio E: IgM paraproteinaemic neuropathies. Curr Opin Neurol 2004;17:599-605.

4 Pugdahl K, Fuglsang-Frederiksen A, de Carvalho M, Johnsen B, Fawcett PR, Labarre-Vila A, Liguori R, Nix WA, Schofield IS: Generalised sensory system abnormalities in amyotrophic lateral sclerosis: a European multicentre study. J Neurol Neurosurg Psychiatry 2007;78:746-749.

-5 Antoine JC, Steck A, Michel D: Fatal peripheral neuropathy with predominant motor involvement associated with anti-MAG IgM monoclonal gammapathy. Rev Neurol (Paris) 1993;149:496-499.

-6 Echaniz-Laguna A, Degos B, Mohr M, Kessler R, Urban-Kraemer E, Tranchant C: A study of three patients with amyotrophic lateral sclerosis and a polyneuropathy resembling CIDP. Muscle Nerve 2006;33:356362 .

-7 Isaacs JD, Dean AF, Shaw CE, Al-Chalabi A, Mills KR, Leigh PN: Amyotrophic lateral sclerosis with sensory neuropathy: part of a multisystem disorder? J Neurol Neurosurg Psychiatry 2007;78:750-753. 
-8 Treon SP, Gertz MA, Dimopoulos M, Anagnostopoulos A, Blade J, Branagan AR, Garcia-Sanz R, Johnson S, Kimby E, Leblond V, Fermand JP, Maloney DG, Merlini G, Morel P, Morra E, Nichols G, Ocio EM, Owen R, Stone MJ: Update on treatment recommendations from the Third International Workshop on Waldenstrom's macroglobulinemia. Blood 2006;107:3442-3446.

\9 Vallat JM, De Mascarel HA, Bordessoule D, Jauberteau MO, Tabaraud F, Gelot A, Vallat AV: Non-Hodgkin malignant lymphomas and peripheral neuropathies: 13 cases. Brain 1995;118:1233-1245.

10 Nakano I: Frontotemporal dementia with motor neuron disease (amyotrophic lateral sclerosis with dementia). Neuropathology 2000;20:68-75.

11 Rowland LP, Sherman WL, Hays AP, Lange DJ, Latov N, Trojaborg W, Younger DS: Autopsy-proven amyotrophic lateral sclerosis, Waldenström's macroglobulinemia, and antibodies to sulfated glucuronic acid paragloboside. Neurology 1995;45:827-829.

12 Sanders KA, Rowland LP, Murphy PL, Younger DS, Latov N, Sherman WH, Pesce M, Lange DJ: Motor neuron diseases and amyotrophic lateral sclerosis: GM1 antibodies and paraproteinemia. Neurology 1993;43:418-420.

-13 Benedetti L, Briani C, Grandis M, Vigo T, Gobbi M, Ghiglione E, Carpo M, Cocito D, Caporale CM, Sormani MP, Mancardi GL, Nobile-Orazio E, Schenone A: Predictors of response to rituximab in patients with neuropathy and anti-myelin associated glycoprotein immunoglobulin M. J Peripher Nerv Syst 2007;12(2):102-107.

14 Shaw PJ: Molecular and cellular pathways of neurodegeneration in motor neurone disease. J Neurol Neurosurg Psychiatry 2005;76:1046-1057.

-15 Rowland LP, Shneider NA: Amyotrophic lateral sclerosis. N Engl J Med 2001;344:1688-1700. 